\title{
Thyroid volumes in US and Bangladeshi schoolchildren: comparison with European schoolchildren
}

\author{
F Xu, K Sullivan, R Houston, J Zhao, W May ${ }^{1}$ and G Maberly \\ Rollins School of Public Health, Emory University, Atlanta, Georgia, USA and ${ }^{1}$ NSW Breast Cancer Institute, Westmead Hospital, Westmead, 214, \\ New South Wales, Australia \\ (Correspondence should be addressed to F Xu, 1600 Clifton Road, NE, CDC Mailstop E-02, Atlanta, Georgia 30333, USA)
}

\begin{abstract}
Objective: The World Health Organization (WHO) recently adopted thyroid volume ultrasonography results from European schoolchildren as the international reference for assessing iodine deficiency disorders. Our objective was to describe thyroid volumes measured by ultrasonography in US and Bangladeshi schoolchildren and compare these with European schoolchildren.

Methods: Cross-sectional studies were performed in schoolchildren in the US $(n=302)$ and Bangladesh $(n=398)$. Data were collected on the following: thyroid size by palpation and ultrasonography; urinary iodine; age; sex; weight; and height.

Results: Applying the new WHO thyroid volume references to the Bangladeshi children resulted in prevalence estimates of enlarged thyroid of $26 \%$ based on body surface area (BSA) and $7 \%$ based on age. In contrast, in the US children, the prevalence estimates were less than $1 \%$ for each reference. In the US children, the best single predictor of thyroid volume was BSA $\left(\mathrm{R}^{2}=0.32\right)$, followed by weight $\left(\mathrm{R}^{2}=0.31\right)$. Using linear regression, upper normal limits (97th percentile) of thyroid volume from US children were calculated for BSA, weight and age, and were found to be lower than the corresponding references based on BSA and age from European schoolchildren.

Conclusions: In areas with malnutrition, such as Bangladesh, the BSA reference should be preferred to the reference based on age. Results from the US children indicated that a thyroid volume reference based on weight alone would perform as well as the one based on BSA. European schoolchildren had larger thyroids than US children, perhaps due to a residual effect of iodine deficiency in the recent past in some areas in Europe.
\end{abstract}

European Journal of Endocrinology 140 498-504

\section{Introduction}

Iodine deficiency is a major public health problem and is the leading preventable cause of mental impairment worldwide (1). The most apparent manifestation of iodine deficiency is goiter, an enlargement of the thyroid gland, and one method for determining the severity of iodine deficiency in a population is by estimating the proportion of children having enlarged thyroid volumes based on ultrasonography. Correct interpretation of ultrasonography results depends upon the availability of a valid reference. Recently the World Health Organization (WHO) has adopted a new thyroid volume reference (2). This reference is based on 3474 European schoolchildren living in areas with a median urinary iodine (UI) level greater than $100 \mu \mathrm{g} / \mathrm{l}$ from four countries: The Netherlands, the Slovak Republic, Austria, and France. Sex-specific upper normal limits of thyroid volume (the 97th percentile) were provided based on age and body surface area (BSA) (3).

We performed similar studies in the United States (US) and Bangladesh in 1996. The US population has been iodine sufficient for decades as evidenced by iodine excretion data from NHANES I and NHANES III surveys, whereas Bangladesh has historically had endemic iodine deficiency disorders (IDD) (4, 5). Recent surveys in Bangladesh have estimated the national prevalence of goiter in schoolchildren to be $50 \%$ and only $44 \%$ of households consume iodized salt (6). The objective of this study was to describe thyroid volumes measured by ultrasonography in US and Bangladeshi schoolchildren and compare these with European schoolchildren.

\section{Subjects and methods}

\section{Subjects}

Schoolchildren from the US and Bangladesh were studied using the same research protocol approved by Emory University Human Investigation Committee; written consent was obtained in the US and verbal consent was obtained in Bangladesh. In the US, 303 
schoolchildren, 7-12 years of age, were studied from seven schools in the Atlanta metropolitan area. One individual was excluded because of cystic lesions on the thyroid gland. In Bangladesh, 400 schoolchildren, 7-10 years of age, from three schools in Saver, located approximately 50 kilometers northwest of Dhaka, were studied. Two subjects were excluded due to missing values on weight or thyroid volume, leaving a sample of 398. Information on age, sex, height, weight, thyroid volume estimated by ultrasonography, goiter by palpation, and urine samples for UI were collected.

\section{Age}

In the US data, exact age was calculated from the date of birth and date of survey. In Bangladesh, a stated age was used. For the calculation of age-based anthropometry, for US children the calculated age in months was used and for the Bangladeshi school children the stated age in years plus 6 months was used. The addition of 6 months was to correct for the usual rounding down of age.

\section{Thyroid volume}

Ultrasound volume was measured according to Brunn et al. (7) using Philips portable ultrasound units (Philips SDR 1200) with a standard 5.0 MHz transducer. The volume of each lobe was calculated by the formula: $\mathrm{V}(\mathrm{ml})=0.000479 \times$ length $\times$ width $\times$ thickness $(\mathrm{mm})$. The thyroid volume was the sum of the volumes of both lobes. The volume of the isthmus was not included. Thyroid glands were classified into 'normal' or 'enlarged' using the Gutekunst reference (thyroid volume-for-age) and the new WHO references (thyroid volume-for-age and thyroid volume-for-BSA $(2,8)$. Thyroid volumes greater than the 97 th percentile were considered abnormally enlarged and those less than or equal to the 97th percentile as normal.

\section{Urinary iodine}

Casual urine samples were collected, packed and transported according to a standard protocol provided by the Program Against Micronutrient Malnutrition (PAMM) laboratory at the Centers for Disease Control and Prevention (CDC). Collection and transport containers were provided by the PAMM laboratory to avoid sample contamination or leakage. For the US study, all UI tests were performed by the PAMM laboratory. In Bangladesh, all UI tests were performed by the Institute of Nutrition and Food Science (INFS) at the University of Dhaka, which participated in a UI laboratory quality assurance program by the PAMM laboratory. UI analysis used a modified acid-digestion method, based on the catalytic effect of iodine on the reaction between cerium IV and arsenic III (Sandell-Kolthoff reaction) (9, 10). One hundred urine specimens from Bangladesh were also tested by the PAMM laboratory and a high correlation was found (Spearman rank correlation $=0.91, P<0.001$ ). Results of analysis in Bangladesh had a higher median than the PAMM laboratory (60.3 vs 50.0, Wilcoxon signed rank test $P<0.001$ ) but there was no statistically significant difference in classifying children as having low UI ( $<10$ vs $>10 \mu \mathrm{g} / \mathrm{dl}$, exact sign test $P=0.13)$.

\section{Anthropometry}

Weights and standing heights were collected. The BSA $\left(\mathrm{m}^{2}\right)$ was calculated by using the formula: BSA = weight $(\mathrm{kg})^{0.425} \times$ height $(\mathrm{cm})^{0.725} \times 71.84 \times 10^{-4}(11)$. Based on the WHO/CDC growth reference, z-scores were calculated for height-for-age (HAZ), weight-for-age (WAZ), and weight-for-height (WHZ) using the Epi Info software (12). Low HAZ was defined as HAZ $<-2$ S.D., low WAZ as WAZ <-2 s.D., and low WHZ as WHZ $<-2$ S.D.

\section{Statistical methods}

Statistical analyses were performed using SAS Version 6.12. The logarithmic transformation was used to normalize the distribution of thyroid volume. The Shapiro-Wilk test was applied to check normality before linear regression was done (13). In the US children, polynomial regressions were used to fit the relation between thyroid volume and various predictors at the normal and natural-log scale. Confidence intervals (CI) for proportions were calculated using Fisher's exact method (14), and CI values for median values were calculated using the method described by Gardner \& Altman (15).

The WHO/UNICEF/ICCIDD (1994) (16) criteria were used to classify a population's severity of IDD based on school-aged children. For UI, the criteria are as follows: mild, 50-99 $\mu \mathrm{g} / \mathrm{l}$; moderate, 20-49 $\mu \mathrm{g} / \mathrm{l}$; severe, $<20 \mu \mathrm{g} / \mathrm{l}$. For the prevalence of goiter and the prevalence of thyroid volume $>97$ th percentile are as follows: mild, 5-19.9\%; moderate, 20-29.9\%; severe, $\geq 30 \%$.

\section{Results}

The mean age of the US schoolchildren was 9.2 years and that of the Bangladeshi children was 8.8 years. Approximately half of the children at each site were male. US children were, on average, taller and heavier than the WHO/CDC growth reference, while Bangladeshi children had a high prevalence of low HAZ (34\%) and low WAZ (54\%) (Table 1).

The median UI level in US children was $282 \mu \mathrm{g} / \mathrm{l}$ and the prevalence of goiter by palpation $2 \%$. The prevalence of enlarged thyroid was $6 \%$ when the Gutekunst reference was applied to the US children. When the new WHO thyroid volume references were applied to the US children the prevalence of enlarged thyroid was $0.3 \%$ 
Table 1 Descriptive statistics of US and Bangladeshi schoolchildren.

\begin{tabular}{|c|c|c|}
\hline & US & Bangladesh \\
\hline Sample size & 302 & 398 \\
\hline $\begin{array}{l}\text { Age in years: } \\
\text { Mean } \\
\text { Range }\end{array}$ & $\begin{array}{c}9.2 \\
7-12\end{array}$ & $\begin{array}{c}8.8 \\
7-10\end{array}$ \\
\hline Male \% & 47 & 53 \\
\hline $\begin{array}{l}\text { Anthropometry } \\
\text { Prevalence of low HAZ }(95 \% \mathrm{Cl}) \\
\text { Prevalence of low WAZ }(95 \% \mathrm{Cl}) \\
\text { Prevalence of low WHZ }(95 \% \mathrm{Cl})\end{array}$ & $\begin{array}{c}0.3 \%(0,1) \\
0 \%(0,1) \\
0 \%(0,2)\end{array}$ & $\begin{array}{l}34 \%(29,39) \\
54 \%(49,59) \\
24 \%(20,29)\end{array}$ \\
\hline BSA: mean $(95 \% \mathrm{Cl})$ & $1.20(1.18,1.22)$ & $0.86(0.85,0.87)$ \\
\hline Median UI level: $\mu \mathrm{g} / \mathrm{l}(95 \% \mathrm{Cl})$ & $282(253,308)$ & $73(66,81)$ \\
\hline Prevalence of goiter by palpation $(95 \%, \mathrm{Cl})$ & $2 \%(1,5)$ & $27 \%(23,32)$ \\
\hline $\begin{array}{l}\text { Prevalence of enlarged thyroid } \\
\text { New WHO reference by age }(95 \% \mathrm{Cl}) \\
\text { New WHO reference by BSA }(95 \% \mathrm{Cl}) \\
\text { Gutekunst reference by age }(95 \% \mathrm{Cl})\end{array}$ & $\begin{array}{c}0.3 \%(0,2) \\
0 \%(0,1) \\
6 \%(4,10)\end{array}$ & $\begin{array}{c}7 \%(4,10) \\
26 \%(21,31) \\
32 \%(28,37)\end{array}$ \\
\hline
\end{tabular}

The prevalence of low anthropometry defined as a z-score <-2 S.D.; due to WHO/CDC growth limitations, WHZ could not be calculated on 134 of the US children or 57 Bangladeshi children; UI results in the US were not available for 20 children; the prevalence of enlarged thyroid based on the new WHO reference for BSA was assessed on only 297 US children whose BSA were within the reference BSA range and on 352 Bangladeshi children for the same reason. Enlarged thyroid volume is defined as $>97$ th percentile.

based on age and $0.0 \%$ based on BSA (Table 1). Since the US population is an iodine-sufficient population, we would expect the prevalence of enlarged thyroid to be around 3\% when the new WHO thyroid volume references are applied to the US sample (because the reference cutoffs were the 97th percentiles). The probability of observing a prevalence of $0.3 \%$ or $0.0 \%$ in the US sample in our study is less than 0.002 assuming the 'true' prevalence to be $3 \%$. Based on the criteria for IDD by WHO/UNICEF/ICCIDD, the US children would be classified as having no IDD for all criteria except the Gutekunst reference where the US children would be classified as having mild IDD.

For the 398 Bangladesh children the median UI was $73 \mu \mathrm{g} / \mathrm{l}$ and the prevalence of goiter by palpation $27 \%$ (Table 1). The prevalence of enlarged thyroid was 32\% based on the Gutekunst reference, $7 \%$ based on the new WHO for-age reference, and $26 \%$ based on the new WHO for-BSA reference. Note that for the WHO reference for BSA, the lowest value of BSA was 0.75, of which $12 \%$ of the children in Bangladesh were below. The median UI and the WHO thyroid volume-forage would classify the Bangladeshi children as having mild IDD, the prevalence of goiter and the new WHO thyroid volume-for-BSA as moderate, and the Gutekunst reference as severe.

Based on the US children, the $\mathrm{R}^{2}$ values for different predictors of thyroid volume and the natural $\log (\ln )$ of thyroid volume were determined (Table 2). The ln of thyroid volume was analyzed because of skewness; after the transformation, the ln of thyroid volume was found to be normally distributed (Shapiro-Wilk test $P=0.82$ ).
BSA $\left(R^{2}=0.32\right)$ and weight $\left(R^{2}=0.29\right)$ were the best predictors of $\ln$ thyroid volume, followed by height $\left(\mathrm{R}^{2}=0.26\right)$ and age $\left(\mathrm{R}^{2}=0.20\right)$; similar results were found in Bangladeshi children, in whom BSA $\left(\mathrm{R}^{2}=\right.$ $0.12)$ predicted better than age $\left(R^{2}=0.07\right)$.

Various multiple linear regression models were estimated to determine how well multiple variables predicted the ln of the thyroid volume. The full model (a model using weight, age, BSA and sex as predictors) had an $\mathrm{R}^{2}$ near 0.35 . Sex became insignificant $(P>0.05)$ once age and weight, or height, or BSA were included in the model. A simple linear model was chosen because none of higher order terms was significant. References of upper limits of normal were derived from the US children for thyroid volume-for-weight, BSA, and age, where references (the 97th percentiles) were lines in parallel with the linear regression lines with the

Table 2 Relation of several factors with thyroid volume in US schoolchildren.

\begin{tabular}{lccc}
\hline & $\boldsymbol{n}$ & $\begin{array}{c}\text { Thyroid volume } \\
\mathbf{R}^{2}\end{array}$ & $\begin{array}{c}\text { In (thyroid volume) } \\
\mathbf{R}^{\mathbf{2}}\end{array}$ \\
\hline BSA $\left(\mathrm{m}^{2}\right)$ & 301 & 0.33 & 0.32 \\
In(BSA) & 301 & 0.32 & 0.32 \\
Weight (kg) & 301 & 0.30 & 0.29 \\
In(weight) & 301 & 0.31 & 0.31 \\
Height (cm) & 302 & 0.26 & 0.26 \\
In(height) & 302 & 0.25 & 0.26 \\
Age (months) & 302 & 0.20 & 0.20 \\
\hline
\end{tabular}

${ }^{*} P<0.008$ for all predictors 
Table 3 Regression equations for predicting thyroid volume (TV) in US children.

\begin{tabular}{lc}
\hline Predictor & \multicolumn{1}{c}{ Regression equation } \\
\hline BSA $\left(\mathrm{m}^{2}\right)$ & 97th: $\ln (\mathrm{TV})=1.565+1.010 \ln (\mathrm{BSA})$ \\
Range: $0.8-1.8 \mathrm{~m}^{2}$ & 50th: $\ln (\mathrm{TV})=1.132+1.010 \ln (\mathrm{BSA})$ \\
& 3rd: $\ln (\mathrm{TV})=0.698+1.010 \ln (\mathrm{BSA})$ \\
Weight $(\mathrm{kg})$ & 97th: $\ln (\mathrm{TV})=-0.305+0.570 \ln$ (weight) \\
Range: $20-90 \mathrm{~kg}$ & 50th: $\ln (\mathrm{TV})=-0.743+0.570 \ln$ (weight) \\
& 3rd: $\ln (\mathrm{TV})=-1.181+0.570 \ln$ (weight) \\
Age (months) & 97th: $\ln (\mathrm{TV})=0.749+0.009$ age \\
Range: $90-155$ month & 50th: $\ln (\mathrm{TV})=0.277+0.009$ age \\
& 3rd: $\ln (\mathrm{TV})=-0.195+0.009$ age \\
\hline
\end{tabular}

intercept increased by 1.881 times the square root of the mean square error of the regression. Regression equations for the 97th, 50th, and 3rd percentiles are given in Table 3. Scatter plots by sex for each of the references with the percentile lines are shown in Fig. 1 and appear to fit the data well - about 3\% of individuals have thyroid volumes beyond the 3rd or 97th percentiles for each predictor.

Comparisons of the various thyroid volume references by age and BSA are shown in Fig. 2. The 97th percentiles for BSA and age from the US children were estimated using the equations in Table 3 and then converted back to normal scale. To account for the rounding down in reporting age, 0.5 was added to the age in years. The 97 th percentiles were then estimated by multiplying the corrected age (in years) with 12 before plugging into the equation using age in months. The 97th percentiles from the US were lower than the new WHO reference from the study by Delange et al. (3). For thyroid volume-for-age, the US references are intermediate between references by Delange et al. (3) and Gutekunst et al. (8).

When the US references were applied to the Bangladeshi children, the prevalence of enlarged thyroid was $17 \%, 56 \%$ and $54 \%$ based on references on age, BSA and weight respectively (Table 1). Compared with the WHO references, the US references indicated a higher prevalence of enlarged thyroid. References based on BSA and weight yielded a similar prevalence of enlarged thyroid, with both references identifying virtually the same children; the concordant rate based on the two references was $98.5 \%$ in Bangladesh and $99.3 \%$ in US.

\section{Discussion}

We found that US children had significantly smaller thyroids than European children. It has been previously reported that iodine deficiency existed in the majority of European countries up to $1992(17,18)$. The study by Aghini-Lombardi et al. (19) showed that thyroid size in children exposed to iodine deficiency in the first years of life might fail to regress completely when the intervention is via iodized salt. In that study, thyroid volume in children born prior to iodine prophylaxis was still larger than that in children from an iodine-sufficient comparison area 10 years after the introduction of iodized salt. A recent study from China found that under optimal iodized salt-intervention conditions, it took 12 months for the prevalence of abnormally large thyroids in schoolchildren with mild to moderate IDD to fall below $5 \%$ (J Zhao, unpublished data). The difference in thyroid volume between the US and European children increased with age or BSA (Fig. 2). A similar pattern was also observed by Aghini-Lombardi et al. (19) in comparing thyroid volume in children from a borderline iodine-deficient area (median UI $=98 \mu \mathrm{g} / \mathrm{l}$ ) with those from an iodine-sufficient area (median UI $=110 \mu \mathrm{g} / \mathrm{l}$ ). These findings suggest that the larger thyroids in European children may result from the residual effects of IDD in the recent past in some European areas, although the difference in dietary factors such as the intake of goitrogens cannot be ruled out.

Another factor that might account for differences between the European and US schoolchildren is the differences in ultrasonography, such as use of different ultrasound equipment and different observers. Note that a $7.5 \mathrm{MHz}$ transducer was used for European children in the study be Delange et al. (3). To our knowledge, no quantitative data comparing different ultrasound units, especially equipment with different transducers, are available, but our experience with ultrasound units with $5 \mathrm{MHz}$ and $7.5 \mathrm{MHz}$ transducers in measuring thyroid size suggests that the impact of difference in the frequency of transducers may be trivial in schoolchildren. In general, the interobserver variation in thyroid ultrasonography is thought to be small and unlikely to account for the large differences in thyroid volumes between the European and US children (20).

In the present study, no difference in thyroid volumes was found between males and females. A number of other studies based on ultrasonography in iodinesufficient areas have also found no difference by sex $(8,20-22)$. Two reasons may account for the larger thyroid volume in girls in European children: first, borderline iodine deficiency affects girls more; and secondly, enlarged thyroid regresses less quickly in girls after iodine intervention.

In this study, a linear relation assumption between thyroid volume and BSA at the natural log-log scale, and between age in months and log thyroid volume was made, and thereafter the 97th percentiles were estimated accordingly. Although the model appears to fit the data well, we may fail to recognize more complicated patterns due to the small sample size.

Based on US schoolchildren, no important differences were found in the prevalence of enlarged thyroid based on BSA versus weight. For survey purposes, it would be simpler to use a reference based on weight rather than 

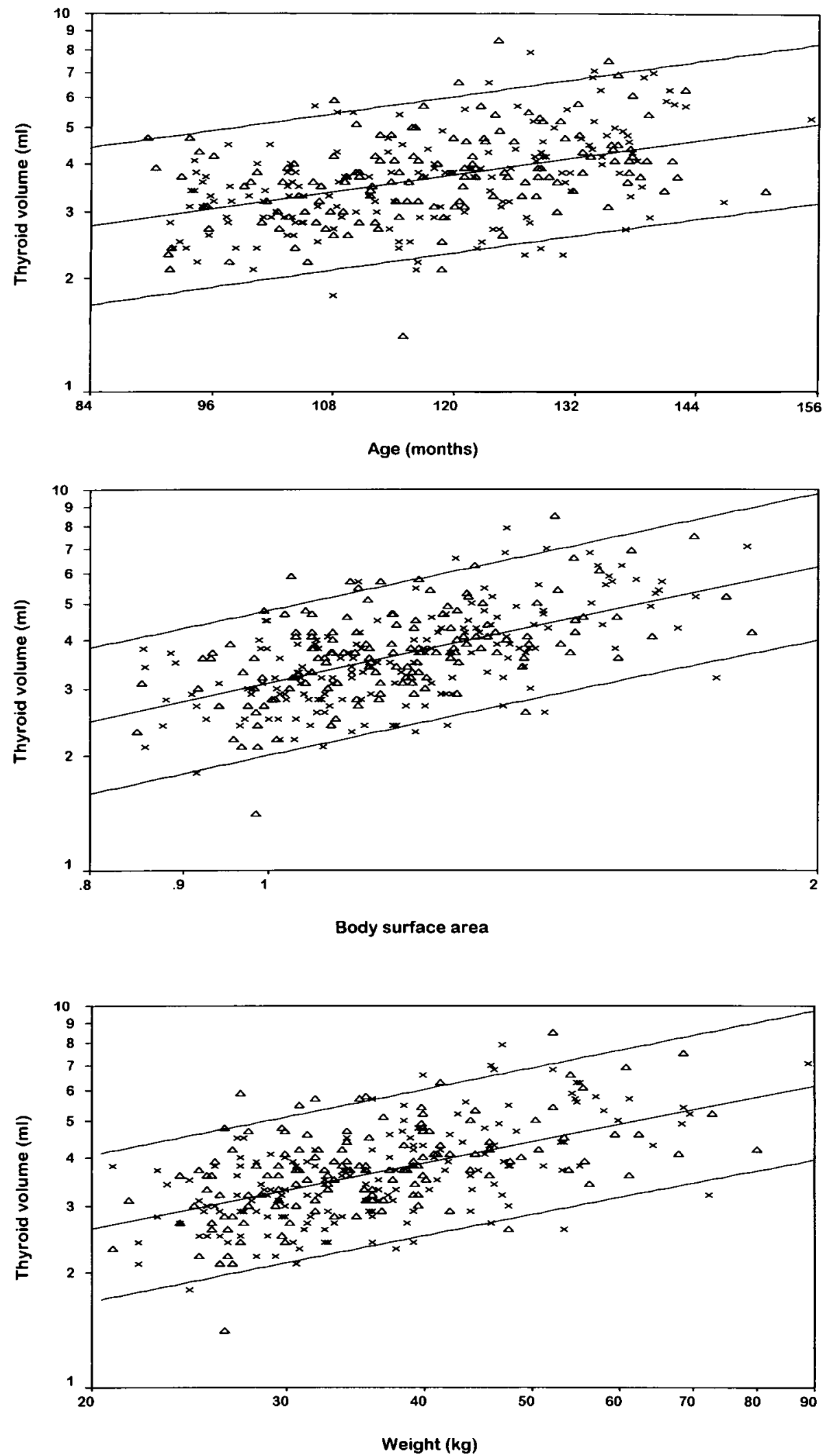

Figure 1 Scatter plots and the estimated lines of 97 th, 50 th and 3rd percentiles of thyroid volume versus age, BSA and weight. Boys $(\triangle)$; girls $(\mathrm{x})$. 

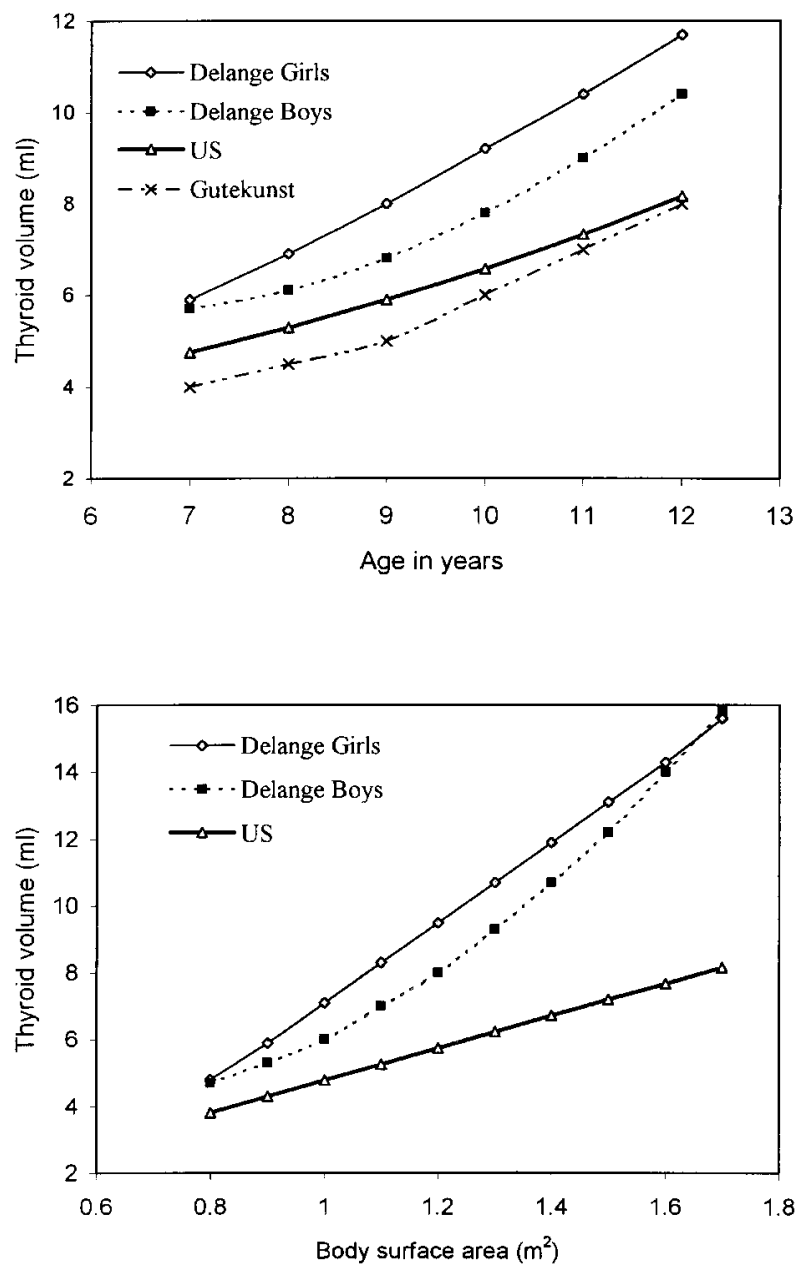

Figure 2 Comparison of the new WHO references with 97th percentiles of thyroid volume from the US population by age and BSA.

BSA because the latter requires the collection of weight and height and the use of a complex formula. We would agree with Delange et al. (3) that the thyroid volume based on BSA should be used in areas with a high prevalence of malnutrition. Because BSA is the best predictor of thyroid volume, at least in the US children and Bangladeshi children, we would recommend that it should always be used, regardless of the nutritional status of the population when both weight and height are available.

\section{Acknowledgements}

We give our special thanks to the personnel involved in the data collection and laboratory analyses; the teachers and staff at the Decatur City Schools, Decatur, GA and Saint Thomas Elementary School, Decatur, GA. Our thanks are also due to Dr Ouazi Salamatullah, Cadi Parvin Banu, and Nama Shaheen from the Institute of Nutrition and Food Science, Dhaka University, Dhaka, Bangladesh, for data collection and laboratory analyses; to Dr Ivan Mendoza, Center for Studies of Sensory Impairment, Aging and Metabolism (CeSSIAM); and to Ms Lisa Lindsay who was involved in data collection in Atlanta and Bangladesh. This work was supported by the Thrasher Research Fund and by UNICEF/Bangladesh.

\section{References}

$1 \mathrm{WHO}$ /UNICEF/ICCIDD. Global prevalence of iodine deficiency disorders. MDIS Working Paper No. 1. Geneva: WHO, 1991.

$2 \mathrm{WHO} / \mathrm{ICCIDD}$. Recommended normative values for thyroid volume in children age 6-15 years. Bulletin of the World Health Organization 199775 95-97.

3 Delange F, Benker G, Caron P, Eber O, Ott W, Peter F et al. Thyroid volume and urinary iodine in European schoolchildren: standardization of values for assessment of iodine deficiency. European Journal of Endocrinology 1997136 180-187.

4 Hollowell JG, Staehling NW, Hannon WH, Flanders DW, Gunter EW, Maberly GF et al. Iodine nutrition in the United States: trends and public health implications. Iodine excretion data from NHANES I and NHANES III surveys (1971-1974 and 19881994). Journal of Clinical Endocrinology and Metabolism 199883 3401-3408.

5 Yusuf HK, Quazi S, Islam MN, Toque T, Rahman KM, Mohiduzzaman $\mathrm{M}$ et al. Current status of iodine-deficiency disorders in Bangladesh (letter). Lancet 1994343 1367-1368.

6 UNICEF. In The State of the World's Children: 1998, pp 98. New York: Oxford University Press, 1998.

7 Brunn J, Block U, Ruf J, Bos I, Kunze WP \& Scriba PC. Volumetrie der schildrüsenlappen mittels real-time-sonographie. Deutsche Medizinische Wochenschrift 1981106 1338-1340.

8 Gutekunst R \& Martin-Teichert H. Requirement for goiter surveys and the determination of thyroid size. In Iodine Deficiency in Europe, pp 109-115. Eds F Delange, JT Dunn \& D Glinoer. New York: Plenum Press, 1993.

9 Sandell EB \& Kolthoff IM. Micro determination of iodine by a catalytic method. Mikrochemica Acta 1937 1 9-25.

10 May SL, May WA, Bourdoux PP, Pino S, Sullivan KM \& Maberly GF. Validation of a simple, manual urinary iodine method for estimating the prevalence of iodine-deficiency disorders, and interlaboratory comparison with other methods. American Journal of Clinical Nutrition 199765 1441-1445.

11 DuBois D \& DuBois EF. Clinical calorimetry. a formula to estimate the approximate surface area if height and weight be known. Archives of Internal Medicine 191617863.

12 Sullivan KM, Gorstein J \& Coulumbier D. Programs for nutritional anthropometry. In Epi Info, Version 6: A Word Processing, Database, and Statistics Program for Epidemiology on IBM Microcomputers, ch. 23, pp 267-288. Eds AG Dean, JA Dean, D Coulombier et al. Atlanta, GA: Centers for Disease Control and Prevention, 1995.

13 Kleinbaum D, Kupper L \& Muller K. Applied Regression Analysis and Other Multivariable Methods, edn 2. Belmont, CA, USA: Duxbury Press, 1988.

14 Gahlinger P \& Abramson J. Computer Program for Epidemiologic Analysis: PEPI version 2. Stone Mountain, GA: USD, Inc., 1995.

15 Gardner M \& Altman D. Statistics with Confidence: Confidence Intervals and Statistical Guidelines. London: British Medical Journal, 1989.

16 WHO/UNICEF/ICCIDD. Indicators for Assessing Iodine Deficiency Disorders and their Control through Salt Iodization. WHO/NUT/94.6. Geneva: WHO, 1994.

17 Gutekunst R \& Delange F. Iodine deficiency in Europe. In S.O.S. for a Billion, ch. 12, pp 199-205. Eds BS Hetzel \& CS Pandav. Delhi: Oxford University Press, 1994. 
18 Delange F, Dunn JT \& Glinoer D (Eds). Iodine Deficiency in Europe. A Continuing Concern. New York: Plenum Press, 1993.

19 Aghini-Lombardi F, Antonangeli L, Pinchera A, Leoli F, Rago T, Bartolomei A et al. Effect of iodized salt on thyroid volume of children living in an area previously characterized by moderate iodine deficiency. Journal of Clinical Endocrinology and Metabolism 199782 1136-1139.

20 Vitti P, Martino E, Aghini-Lombardi F, Rago T, Antonangeli L, Maccherina D et al. Thyroid volume measurement by ultrasound in children as a tool for the assessment of mild iodine deficiency. Journal of Clinical Endocrinology and Metabolism 199479 600-603.
21 Ivarsson SA, Persson PH \& Ericsson UB. Thyroid gland volume as measured by ultrasonography in healthy children and adolescents in a non-iodine deficient area. Acta Paediatrica Scandinavica 198978 633-634.

22 Ueda D. Normal volume of the thyroid gland in children. Journal of Clinical Ultrasound 199018 455-462.

Received 1 October 1998

Accepted 12 February 1999 